\title{
Histopathological Spectrum of Salivary Gland Tumors in Tripura, India: A Seven Year Study
}

\author{
Dr. Alpana Banerjee ${ }^{1}$, Dr. Manasi Saha (Ray) ${ }^{2}$ \\ ${ }^{I}$ Assistant Professor, Department of Pathology, Agartala Government Medical College \& GBP Hospital, \\ ${ }^{2}$ Associate Professor, Department of Pathology, Agartala Government Medical College and GBP Hospital.
}

\begin{abstract}
Background: Salivary gland tumors are rare neoplasms that generate interest due to their histopathological diversity. Several studies have reported a significant difference in the global distribution of salivary gland tumors, but no formal study has been carried out in this part of the globe.

Aim: To study the histopathological spectrum of salivary gland lesions and to know the pattern of distribution in Tripura, a state in North Eastern India.

Materials and Methods: This is a 7 years (2010-2016) retrospective study of all salivary gland tumor specimens received at our referral teaching hospital in Tripura, India. All the slides were reviewed by the authors. Clinical details were obtained from the archives. Data thus collected were analyzed.

Results: A total of 46 cases were studied during the study period. Of them 37 cases were benign and 9 cases were malignant. Age ranged from 12 years to 88 years with an overall female preponderance. Parotid (78.26\%) was the commonest gland involved. Both benign (29 out of 36 cases) and malignant tumors ( 7 out of 9 cases) were more common in parotid. Pleomorphic adenoma was the commonest benign tumor (25 cases) and adenoid cystic carcinoma was the commonest malignancy (4 cases).

Conclusion: The principal site of salivary gland tumors was the parotid gland and pleomorphic adenoma outnumbered all the other tumors. Adenoid cystic carcinoma was the most common malignant tumor.
\end{abstract}

Keywords: Salivary gland tumor, pleomorphic adenoma, adenoid cystic carcinoma.

\section{Introduction}

Tumors of salivary glands are relatively infrequent and account for less than $2 \%$ of all human tumors. ${ }^{1}$ They occur in 1 in 100,000 individuals comprising $3 \%$ of all head and neck neoplasms. ${ }^{2}$ Salivary gland tumors are of particular interest to both histopathologists and surgeons because of their varied histological and biological characteristics and the difficulties involved in management. ${ }^{3}$ The incidence of salivary gland tumors is claimed to be influenced by geographical and racial factors, which makes it difficult to establish global estimates. ${ }^{4,5,6,7}$ In view of the fact that these tumors are treated on the basis of their histological and local findings, correct histological diagnosis is obligatory. ${ }^{3}$

Local records are a useful strategy for the analysis of the distribution and particular features of salivary gland tumors in a specific population. Tripura is a North Eastern state of India where salivary gland tumors constitute $0.57 \%$ of all cancers in males and $0.13 \%$ of malignancies in females. ${ }^{8}$ The goal of this study was to retrospectively analyze 46 neoplastic lesions of salivary gland and to reveal the pattern of distribution of various salivary gland tumors in Tripura.

\section{Materials And Methods}

The present study was a seven year (2010-2016) retrospective study of all salivary gland tumor specimens received at histopathology section of Department of Pathology, Agartala Government Medical College and Govind Ballabh Pant Hospital (AGMC \& GBP Hospital). AGMC is the major tertiary health-care teaching institute offering histopathology services to the entire state of Tripura. Samples inadequate for processing and reporting were excluded from the study. Specimens were subjected to routine processing and paraffin embedding and stained with hematoxylin and eosin ( $\mathrm{H}$ and $\mathrm{E})$. All the histopathology slides were reviewed by the authors and classified according to the World Health Organization (WHO) histological typing of tumors 2005. Fresh sections of tissue blocks and restaining of the slides were performed whenever required. Clinical data (age, sex and site) were obtained from laboratory archives. Data thus collected were analyzed.

\section{Results}

Forty-six salivary gland neoplasms were diagnosed between January 2010 and December 2016. Their ages ranged from 12 years to 88 years. Female predominance was more marked among malignancies (M:F = $1: 2)$ than benign tumors (1: 1.04). Among the 46 cases, benign tumors with 37 cases $(80.43 \%)$ outnumbered the malignant ones with 9 cases $(19.57 \%)$. 
Pleomorphic adenoma (67.57\%) was the most common benign lesion with M:F ratio of 1.08:1 followed by Warthin tumor (13.51\%) with M:F ratio of 2:3 [Table 1]. Adenoid cystic carcinoma (44.44\%) was the most common malignant tumor with female predominance (M:F=1:3). Acinic cell carcinoma, salivary duct carcinoma, carcinoma ex pleomorphic adenoma, poorly differentiated squamous cell carcinoma and neuroendocrine tumor were seen in one case each [Table 2].

Table 1: Frequency of benign tumors and their sex distribution.

\begin{tabular}{|l|c|c|c|}
\hline Benign tumor & No & \% & M:F \\
\hline Pleomorphic adenoma & 25 & 67.57 & $1.08: 1$ \\
\hline Warthin tumor & 5 & 13.51 & $2: 3$ \\
\hline Basal cell adenoma & 2 & 5.41 & $1: 1$ \\
\hline Myoepithelioma & 2 & 5.41 & $1: 1$ \\
\hline Benign lymphoepithelial lesion & 1 & $2: 7$ & All female \\
\hline Benign myofibroblastic tumor & 1 & $2: 7$ & All male \\
\hline Schwannoma & 1 & $2: 7$ & All female \\
\hline Total & $\mathbf{3 7}$ & $\mathbf{1 0 0}$ & $\mathbf{1 : 0 6}$ \\
\hline
\end{tabular}

Table 2: Frequency of malignant tumors and their sex distribution.

\begin{tabular}{|l|c|c|c|}
\hline \multicolumn{1}{|c|}{ Malignant tumor } & No & \% & M:F \\
\hline Adenoid cystic carcinoma & 4 & 44.44 & $1: 3$ \\
\hline Acinic cell carcinoma & 1 & 11.11 & All female \\
\hline Salivary duct carcinoma & 1 & 11.11 & All male \\
\hline Carcinoma ex pleomorphic adenoma & 1 & 11.11 & All male \\
\hline $\begin{array}{l}\text { Poorly differentiated squamous cell } \\
\text { Carcinoma }\end{array}$ & 1 & 11.11 & All female \\
\hline Neuroendocrine tumor & 1 & 11.11 & All female \\
\hline \multicolumn{1}{|c|}{ Total } & $\mathbf{9}$ & $\mathbf{1 0 0}$ & $\mathbf{1 : 2}$ \\
\hline
\end{tabular}

Salivary gland tumors were uncommon below the age of 20 and all the 3 cases were benign. No malignant neoplasm was seen below 30 years. Most common incidence of benign tumors was among the age group of 41-50 years (10 cases) followed by more than 60 years age group with 9 cases. A bimodal peak of malignancies was noted in 41-50 years and more than 60 years age group comprising 3 cases each [Table 3].

Table 3: Age correlation of benign and malignant salivary gland tumors.

\begin{tabular}{|c|c|c|c|c|c|c|c|c|c|c|c|c|}
\hline Tumor & \multicolumn{2}{|c|}{$<20$} & \multicolumn{2}{|c|}{$21-30$} & \multicolumn{2}{|c|}{$31-40$} & \multicolumn{2}{|c|}{$41-50$} & \multicolumn{2}{|c|}{$51-60$} & \multicolumn{2}{|c|}{$>60$} \\
\hline & No & $\%$ & No & $\%$ & No & $\%$ & No & $\%$ & No & $\%$ & No & $\%$ \\
\hline Benign tumor & 3 & 8.1 & 4 & 10.8 & 5 & 13.5 & 10 & 27.03 & 6 & 16.23 & 9 & 24.32 \\
\hline Malignant tumor & - & - & - & - & 2 & 22.22 & 3 & 33.33 & 1 & 11.11 & 3 & 33.33 \\
\hline
\end{tabular}

Parotid (78.26\%) was the commonest gland involved followed by submandibular gland (13.04\%). Both benign (29 cases) and malignant tumors (7 cases) were common in parotid followed by submandibular gland [Table 4].

Table 4: Site distribution of salivary gland tumors.

\begin{tabular}{|l|c|c|c|}
\hline \multicolumn{1}{|c|}{ Salivary gland } & No of benign & No of malignant & Total \\
\hline Parotid & 29 & 7 & $36(78.26 \%)$ \\
\hline Submandibular & 5 & 1 & $6(13.04 \%)$ \\
\hline Minor salivary gland & 3 & 1 & $4(8.69 \%)$ \\
\hline
\end{tabular}

Pleomorphic adenoma was the commonest benign tumor (25 cases) affecting parotid, submandibular and minor salivary glands (Fig.1). Warthin tumor, basal cell adenoma, myoepithelioma, benign lymphoepithelial lesion and schwannoma affected only the parotid gland except one case of benign myofibroblastic tumor that involved submandibular gland [Table 5].

Table 5: Benign tumors and site correlation.

\begin{tabular}{|l|c|c|c|c|c|c|c|c|}
\hline \multicolumn{1}{|c|}{ Benign } & \multicolumn{2}{|c|}{ Parotid } & \multicolumn{2}{c|}{ Submandibular } & \multicolumn{2}{c|}{ Minor } & \multicolumn{2}{c|}{ Total } \\
\hline $\begin{array}{l}\text { Pleomorphic } \\
\text { adenoma }\end{array}$ & No & $\%$ & No & $\%$ & No & $\%$ & No & $\%$ \\
\hline Warthin tumor & 5 & 72 & 4 & 16 & 3 & 12 & 25 & 67.57 \\
\hline Basal cell adenoma & 2 & 100 & - & - & - & - & 5 & 13.51 \\
\hline Myoepithelioma & 2 & 100 & - & - & - & - & 2 & 5.41 \\
\hline $\begin{array}{l}\text { Benign } \\
\text { lymphoepithelial } \\
\text { lesion }\end{array}$ & 1 & 100 & - & - & - & - & 2 & 5.41 \\
\hline $\begin{array}{l}\text { Benign } \\
\text { myofibroblastic }\end{array}$ & - & - & 1 & 100 & - & - & 1 & 2.70 \\
\hline
\end{tabular}




\begin{tabular}{|l|l|l|l|l|l|l|l|l|}
\hline tumor & & & & & & & & \\
\hline Schwannoma & 1 & 100 & - & - & - & - & 1 & 2.70 \\
\hline
\end{tabular}

Parotid was the commonest gland involved by malignancy ( 7 out of 9 cases) and one case each affected submandibular and minor salivery glands. Adenoid cystic carcinoma was the most common malignancy consisting 4 out of 9 cases (Fig.2) and two cases of which involved parotid gland. Acinic cell carcinoma, salivary duct carcinoma, carcinoma ex pleomorphic adenoma, poorly differentiated squamous cell carcinoma and neuroendocrine tumor involved only the parotid gland (one case each) [Table 6].

Table 6: Malignant tumors and site distribution.

\begin{tabular}{|l|c|c|c|c|c|c|c|c|}
\hline \multicolumn{1}{|c|}{ Malignant } & \multicolumn{2}{c|}{ Parotid } & \multicolumn{2}{c|}{ Submandibular } & \multicolumn{2}{c|}{ Minor } & \multicolumn{2}{c|}{ Total } \\
\hline & No & $\%$ & No & $\%$ & No & $\%$ & No & $\%$ \\
\hline Adenoid cystic carcinoma & 2 & 50 & 1 & 25 & 1 & 25 & 4 & 44.44 \\
\hline Acinic cell carcinoma & 1 & 100 & - & - & - & - & - & 11.11 \\
\hline Salivary duct carcinoma & 1 & 100 & - & - & - & - & - & 11.11 \\
\hline $\begin{array}{l}\text { Carcinoma ex pleomorphic } \\
\text { adenoma }\end{array}$ & 1 & 100 & - & - & - & - & - & 11.11 \\
\hline $\begin{array}{l}\text { Poorly differentiated } \\
\text { squamous cell carcinoma }\end{array}$ & 1 & 100 & - & - & - & - & - & 11.11 \\
\hline Neuroendocrine tumor & 1 & 100 & - & - & - & - & - & 11.11 \\
\hline
\end{tabular}

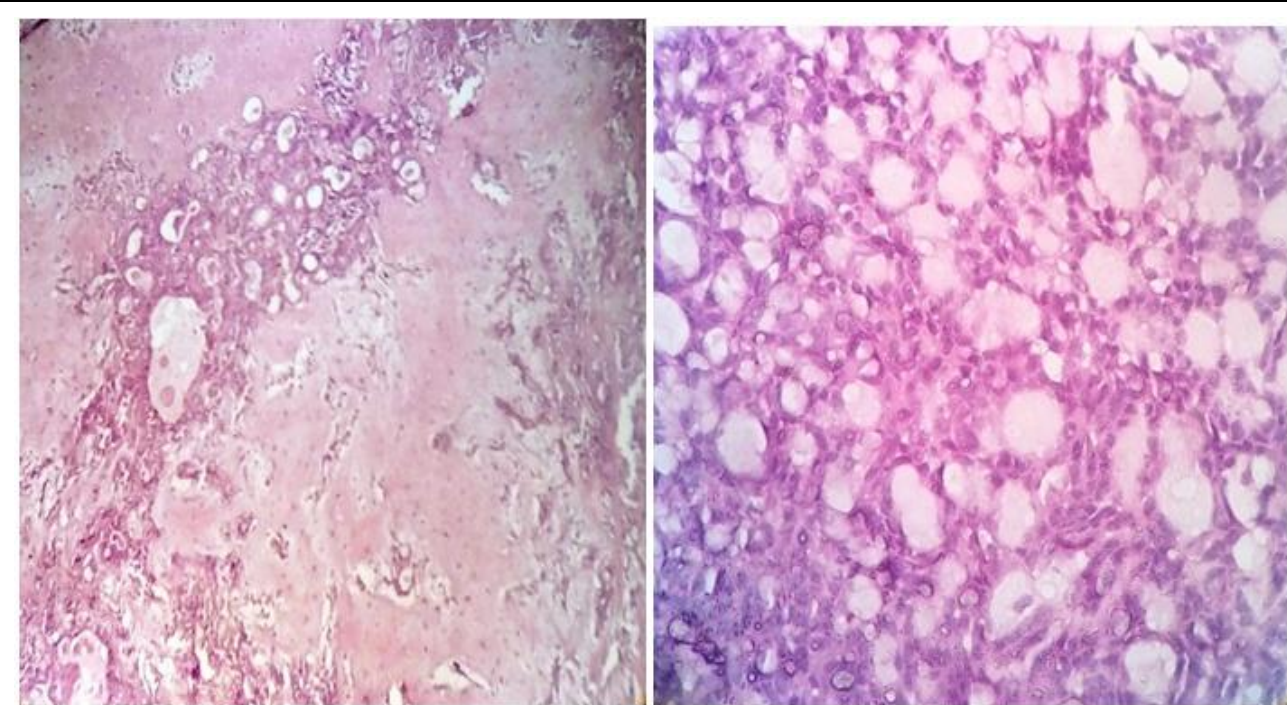

Fig 1 Pleomorphic adenoma showing both epithelial and Fig 2. Adenoid cystic carcinoma showing small mesenchymal components (H\&E, X50) cells arranged around gland like spaces (H\&E, X 400)

\section{Discussion}

Tumors of salivary glands are relatively uncommon; however, their similar clinical presentation, but varied morphologic configuration and relatively unpredictable prognostic course continue to attract attention. As stated in the literature environmental and racial factors have a considerable impact upon the geographical distribution of these neoplasms. ${ }^{6}$

In the present study, among the 46 neoplastic lesions benign tumors predominated over malignant ones similar to a series of 124 cases by Vagas et al in a Brazilian population. ${ }^{5}$ Studies by Laishram et al in Manipur and Ahmad et al in Kashmir were also comparable to our study. ${ }^{4,6}$ Our study showed high incidence of both benign and malignant tumors in $5^{\text {th }}$ decade and after 60 years. However Satko et al and Ahmad et al reported the highest incidence of benign tumors in the $3^{\text {rd }}$ to $4^{\text {th }}$ decade and malignant tumors in $4^{\text {th }}$ to $5^{\text {th }}$ decade of life..$^{6,9}$ The study in Manipur found that the mean age for benign and malignant tumors were 40.2 years and 46.86 years respectively. According to the variable "gender", most of the studies reviewed show a female predominance similar to our findings. ${ }^{5,10}$ In contrast, Frade Gonzalez et al observed a predominance of salivary gland tumors in the male group $(58.75 \%)$ and in the $7^{\text {th }}$ decade of age. ${ }^{11}$ Similarly, Laishram et al found male predominance in benign lesions in Manipur and Ahmad et al observed that males are more affected by both benign and malignant neoplasms of salivary glands in Kashmir. ${ }^{4,6}$ This may be due to the regional differences or the size of the samples used in each study.

The parotid gland was the most commonly involved site in this series accounting for $78.26 \%$ cases followed by submandibular (13.04\%) and minor salivary glands. In the Western world, parotid tumors were overwhelmingly preponderant comprising $70-86 \%$ of salivary gland tumors where as African series show modest prominence of parotid tumors relative to other salivary gland tumors. Pleomorphic adenoma was the 
commonest benign tumor in our study comprising $67.57 \%$ cases which is lower than the neighboring state Manipur (76.79\%) [Fig.1]. ${ }^{4}$ However, pleomorphic adenoma had been listed universally as the most common tumor in all the studies with a range of $40-72 \% .^{10,14,15}$ Warthin tumor $(13.51 \%)$ was the second commonest benign tumor similar to the observation of Chung et al. ${ }^{16}$ Out of 25 cases of pleomorphic adenomas 18 involved parotid, 4 involved submandibular gland and 3 cases involved minor salivary glands. All the five cases of Warthin tumor affected only the parotid gland, which is similar to the finding reported by Laishram et al. ${ }^{4}$

In the present series adenoid cystic carcinoma was the most common salivary gland tumor comprising $44.44 \%$ cases (4 cases out of 9 malignancies)[Fig.2]. Ahmad et al and Rewsuwan et al also reported similar observation in their studies. ${ }^{6,17}$ In contrast to the above finding mucoepidermoid carcinoma was the most common malignant tumor in majority of the studies. ${ }^{4,5}$ Fifty percent ( 2 out of 4 cases) of adenoid cystic carcinomas originated from parotid gland and one cases each from submandibular and minor salivary gland. Rest one case each of acinic cell carcinoma, salivary duct carcinoma, carcinoma ex pleomorphic adenoma, poorly differentiated squamous cell carcinoma and neuroendocrine tumor were arising from parotid gland. No case of mucoepidermoid carcinoma was encountered in this series.

In our study, out of 4 minor salivary gland tumors 3 were benign (diagnosed as pleomorphic adenoma) and only one case was malignant (adenoid cystic carcinoma).

\section{Conclusion}

In this retrospective study, major salivary glands were more affected than minor glands and parotid being the most common site. Pleomorphic adenoma and adenoid cystic carcinoma were the most common benign and malignant tumor respectively in this North Eastern state of India. Females were predominantly affected by both benign and malignant lesions. The study contributes to the awareness of pathological features and age, gender, site distribution of the salivary gland tumors. Factors that influence behavior and prognosis of these tumors should be investigated further.

\section{Acknowledgments}

Our great gratitude to all the technicians of histopathology section, Department of Pathology, AGMC \& GBP Hospital for their invaluable support in retrieving slides from archives and taking new sections including staining whenever required. Sincere thanks are extended to laboratory attendants for helping us collecting data from the records.

\section{References}

[1]. Ezeanolue BC. Salivary gland neoplasms: A descriptive analysis of the pattern seen in Enugu. West Afr J Med 1999; 18: 179-82.

[2]. Ellis GL, Auclair PL. Tumors of the salivary glands. $3^{\text {rd }}$ edition. Armed Forces Institute of Pathology: Washington;1996.

[3]. Vuhahula EA. Salivary gland tumors in Uganda: Clinical pathological study. Afr Health Sci 2004; 4 : 15-23.

[4]. Laishram RS, Kumar KA, Pukhrambam GD, Laishram S, Debnath K. Pattern of salivary gland tumors in Manipur, India: A 10 year study. South Asian J Cancer 2013; 2: 250-3.

[5]. Vargas PA, Gerhard R, AraujoFilho VJ, de Castro IV. Salivary gland tumors in a Brazilian population: A retrospective study of 124 cases. Rev Hosp Clin Fac Med Sao Paulo 2002; 57: 271-6.

[6]. Ahmad S, Lateef M, Ahmad R. Clinicopathological study of primary salivary gland tumours in Kashmir. JK Pract 2002; 9: 231-3.

[7]. Ochicha O, Malami S, Mohammed A, Atanda A. A histological study of salivary gland tumors in Kano, north Nigeria. Indian J of Pathol Microbiol 2009; 52: 473-6.

[8]. National Cancer Registry Programme. Population based cancer registry, Tripura. Regional Cancer Centre, Agartala. Indian Council of Medical Research. $2010: 688-705$.

[9]. Satko I, Stanko P, Longauerova I. Salivary gland tumours treated in the stomatological clinics in Bratislava. J Craniomaxillofac Surg 2000; $28: 56-61$.

[10]. Ito FA, Ito K, Vargas PA, de Almeida OP, Lopes MA. Salivary gland tumors in a Brazilian population : A retrospective study of 496 cases. Int J Oral Maxillofac Surg 2005; 34 : 533-6.

[11]. Frade Gonzalez C, Lozano Ramirez A, Garcia Caballero T, Labella Caballero I. Epidemiological study of salivary gland tumours. Rev Laryngol Otol Rhinol (Bord) 1999; 120: 331-6.

[12]. Lingen MW. Salivary glands. In: Kumar V, Abass AK, Aster JC. Robbin, Cotran, editors. Pathologic basis of disease. $9^{\text {th }}$ edition. Philadelphia : Elsevier Saunders : 2015. P. $742-8$.

[13]. Masanja MI, Kalvanyama BM, Simon EN. Salivary gland tumours in Tanzania. East Afr Med J 2003; 80 : 429-34

[14]. Li LJ, Li Y, Wen YM, Liu H, Zhao HW. Clinical analysis of salivary gland tumor cases in West China in past 50 years. Oral Oncol.2008; 44: 187-92.

[15]. Tilakarante WM, Jayasooriya PR, Tennakoon TM, Saku T. Epithelial salivary tumors in SriLanka: a retrospective study of 731 cases. Oral Surg Oral Med Oral Pathol Oral Radiol Endod. 2009; 108: 90-8.

[16]. Chung YF, Khoo ML, Heng MK, Hong GS, Soo KC. Epidemiology of Warthin's tumour of the parotid gland in an Asian population. Br J Surg 1999; $86: 661-4$.

[17]. Rewsuwan S, Settakorn J, Mahanupab P. Salivary gland tumors in Maharaj Nakorn Chiang Mai Hospital: A retrospective study of 198 cases. Chiang Mai Med Bull 2006; 45: 45-53. 